\title{
Eficácia de políticas de acesso ao ensino superior privado na contenção da evasão
}

\author{
Adriano Maniçoba da Silva \\ Beatriz Carolini Silva Santos
}

Resumo: A evasão consiste num problema importante no âmbito educacional por causar ociosidade de recursos. O PROUNI (Programa Universidade para Todos) e o FIES (Financiamento Estudantil) têm subsidiado o ingresso de estudantes em Instituições de Ensino Superior (IES) privadas. Esses incentivos minimizam a motivação financeira que pode gerar evasão. O objetivo desta pesquisa foi verificar o efeito da concessão de bolsas do PROUNI e FIES na contenção da evasão. Com análise de dados em painéis estimou-se quatro modelos, sendo significante o modelo por efeitos aleatórios. Os resultados apontaram que as bolsas ofertadas pelo PROUNI têm correlação negativa com a evasão e, com menor magnitude, o FIES apresentou relação positiva. Desta forma, conclui-se que o PROUNI se apresenta como uma política mais eficaz à contenção da evasão do que o FIES.

Palavras-chave: PROUNI. FIES. Evasão. Políticas governamentais.

\section{Access policy effectiveness to higher private education in contention of student dropout}

Abstract: The evasion is an important problem in the educational scope because of idleness of resources. The PROUNI (Programa Universidade para Todos) and the FIES (Fundo de Financiamento Estudantil) have subsidized the entry of students in private Higher Education Institutions (HEI). Those incentives decrease the financial motivation that can generate evasion. The objective of this research was check the impact of PROUNI and FIES to contain evasion. With panel data analysis, we estimated four models, which was chosen the random effects. The results showed that the scholarships offered by PROUNI had negative correlation with evasion, and, the relation of FIES was positive. We conclude that PROUNI was a more effective policy to contain evasion than FIES.

Key words: PROUNI. FIES. Evasion. Government policies. 


\section{Introdução}

Compreende-se como evasão a saída definitiva do estudante do seu curso. Este fenômeno pode ser considerado um problema de âmbito internacional tanto para as Instituições de ensino superior (IES) públicas, devido à ociosidade de recursos, como para as IES privadas por implicar em perda de receita. A evasão prejudica o resultado dos sistemas educacionais, trazendo ineficiência de recursos sociais e econômicos.

Alguns motivos que causam a evasão são: a baixa eficiência e a precariedade do ensino médio, que não garantem as competências suficientes para o candidato ingressar no ensino superior; insatisfação com a baixa qualidade dos serviços oferecidos pela IES; a escolha precoce da especialização profissional; dificuldades com alimentação, transporte e ambientação na IES (LOBO, 2012). Com problemas como esse é importante que o Estado tenha a iniciativa de implementar políticas públicas de acesso e manutenção do aluno no ensino superior.

As políticas públicas são um conjunto de programas, atividades e ações concebidas pelo Estado, com a participação de entidades privadas ou públicas tendo o intuito de garantir determinado direito de cidadania para algum seguimento social, étnico ou econômico (CUNHA, 2006).

O programa universidade para todos (PROUNI) é um exemplo de política pública. O programa prioriza a diversidade cultural e social que há no país e busca oferecer mais oportunidades às pessoas de baixa renda. Por meio desse programa, os estudantes que não possuem condições financeiras para arcar com os custos das mensalidades do curso escolhido, podem concorrer a bolsas integrais ou parciais em IES privadas dependendo da nota alcançada pelo mesmo no exame nacional do ensino médio (ENEM).

Outra política pública de acesso ao ensino superior em IES privadas é o financiamento estudantil (FIES), que consiste num apoio financeiro que subsidia a graduação de estudantes matriculados em IES privadas com conceitos positivos no Exame Nacional de Cursos (ENC), também conhecido como Sistema Nacional de Avaliação do Ensino Superior (SINAES). Com esse programa, o estudante pode financiar seu curso por meio de menores parcelas e empo maior para pagar as mensalidades da IES. Dado o panorama da evasão e das políticas públicas que podem mitigar seu efeito, o objetivo deste estudo foi verificar o efeito das políticas de acesso ao ensino superior (PROUNI e FIES) em IES privadas na contenção da evasão.

Será abordada na próxima seção a importância das políticas públicas e de sua avaliação. 


\section{Avaliação de políticas públicas}

O amadurecimento da sociedade brasileira democrática faz com que o Estado seja cada vez mais questionado em relação ao seu desempenho e a efetividade de suas ações a fim de melhorar a realidade socioeconômica. Desse modo, é importante acompanhar as políticas públicas concebidas para o desenvolvimento socioeconômico da sociedade (BRASIL. SENADO FEDERAL, 2015).

O Governo Federal criou alguns programas que possibilitam o acesso à educação para pessoas consideradas excluídas. Os principais programas são: Programa de Financiamento Estudantil (FIES), Programa Universidade para todos (PROUNI), Programa de Inclusão social e racial (COTAS), para os vestibulares nas instituições públicas de ensino superior e, o Programa INCLUIR, dirigido às pessoas portadoras de deficiência. Seguindo a orientação de políticas públicas neoliberais, houve no Brasil uma ampliação da quantidade de instituições de ensino superior e consequentemente das vagas ofertadas no setor privado. Devido a esse fato, é importante que o Estado proporcione políticas públicas voltadas ao acesso de estudantes de baixa renda ao ensino superior (BONETI, 2003).

Na perspectiva da população, as políticas públicas que são aprovadas são respostas dos representantes eleitos para atender as necessidades do País. Essas políticas correspondem a direitos assegurados constitucionalmente ou que se estabelecem devido ao reconhecimento da sociedade. É importante que haja uma avaliação anterior à implementação de determinada política pública para, assim, antecipar seus efeitos e o desenvolvimento de métricas e aferição do desempenho. Primeiramente, deve-se reconhecer o problema que se deseja tratar, se há relação de causalidade entre o resultado e a intervenção governamental e, em qual magnitude, a política pública poderá contribuir para solucioná-lo. As avaliações que acontecem durante ou depois da efetivação de uma política pública, tem a vantagem de conhecer alguns dos efeitos produzidos, de modo que seja possível comparar a realidade com o que foi planejado, estudar as alterações nas principais variáveis envolvidas e o resultado gerado no estrato da sociedade que se gostaria de impactar (BRASIL. SENADO FEDERAL, 2015).

A partir do século XX, com o fortalecimento dos Estados Nacionais, houve a necessidade de modernizar a gestão pública. Desse modo, a avaliação de políticas públicas firmou-se como uma área de estudos. O desenvolvimento da área se deu pela importância de planejar cientificamente as ações do governo, e para que essas ações possam ser exploradas por pesquisadores aptos a avaliar com isenção política os benefícios alcançados pela população. Mesmo sabendo que a avaliação de políticas públicas, com a participação da 
sociedade, é um processo fundamental para a democracia no país, ainda há dois pontos que merecem atenção: as avaliações das políticas públicas não são feitas com a intensidade que se deveria e, as pesquisas que se dedicam ao aprofundamento do assunto são insuficientes (MUGNOL; GISI, 2013).

Pode-se definir a avaliação como sendo uma análise ponderada e sistemática dos resultados de um programa ou uma política, em comparação com um conjunto de padrões explícitos ou implícitos, com o intuito de ter uma contribuição para o seu aperfeiçoamento (WEISS, 1998 apud MUGNOL; GISI, 2013).

Avaliar uma política é investigar quais foram seus efeitos para a sociedade, a fim de proporcionar insumos para que possa dar continuidade ou ser ampliada e, modificar algum aspecto de sua execução ou até mesmo para decidir seu término (BONETI, 2003).

Com o processo avaliativo espera-se obter conhecimento que permita avaliar o resultado efetivo das ações governamentais e também racionalizar os processos de decisão, demonstrando por intermédio de indicadores de base científica a sua legitimação. Essa avaliação de racionalização dos processos decisórios, que é uma ferramenta de planejamento e também um mecanismo para reduzir gastos públicos, foi se apresentando cada vez mais factível, o que reforçou a compreensão da avaliação a serviço da área pública (SOUZA, 2006).

Para colaborar na tomada de decisões e ter controle das ações relacionadas à população, é preciso fazer uma avaliação dos projetos e programas governamentais. As avaliações asseguram a consistência dos projetos que obtiveram sucesso, os quais passam a ter sustentabilidade política, por serem fomentadas na transparência da gestão pública e na satisfação dos usuários. Há diversos modos de realizar uma avaliação, um deles é avaliação acadêmica, mais formal, com interesse em estudar a efetividade das políticas, seus impactos e benefícios. Um outro modo é a avaliação promovida durante o período em que foram implantadas as políticas e programas governamentais, com foco na análise de sua eficiência e eficácia (CUNHA, 2006).

Na próxima seção será apresentado o Programa Universidade para Todos (PROUNI).

\section{PROUNI}

No Brasil, ainda é limitado o acesso ao ensino superior pela oferta de vagas nas instituições públicas de ensino. Mesmo que o acesso à educação seja um direito 
constitucional, não é possível favorecer todos que desejam estudar, devido às instituições terem um limite de infraestrutura para atender uma quantidade determinada de estudantes.

Com isso, é importante que o Estado privilegie a consolidação de políticas afirmativas, de acordo com a noção de igualdade e isonomia. O mercado de trabalho exige qualificação e formação profissional, por isso, é necessário a conclusão da formação básica e o ingresso na universidade, já que as transformações do mercado de trabalho vêm aumentando a competitividade pelo emprego resultando em pressão sobre a educação superior (COSTA; FERREIRA, 2012).

De acordo com o censo de 2012, apenas $11,3 \%$ da população tinha ensino superior completo, ou seja, o acesso ao ensino superior ainda é relativamente baixo (ROCHA, 2011). Em 2004, foi criado o programa universidade para todos (PROUNI) que oferece bolsas de estudo integrais e parciais em cursos de graduação e sequênciais de formação específica, em IES privadas (COSTA; FERREIRA, 2012).

Segundo Costa e Ferreira (2017), o PROUNI possibilitou o aumento de matrículas no setor privado a uma média anual de 5,15\%. Entretanto, segundo as autoras, a ociosidade das bolsas foi de $30 \%$ e a evasão teve média de 10,4\%, sobretudo em função das restrições econômicas dos estudantes.

Apesar do aumento do número de matrículas, Fontele e Crisóstomo (2016), apontaram dificuldades encontradas pelos estudantes bolsistas no que tange à oferta de cursos, pelo fato desta ser desenhada pelas perspectivas do mercado de trabalho e por conveniência das IES.

O PROUNI foi institucionalizado pela Lei ${ }^{\circ} 11.096$ (BRASIL, 2005), em 13 de janeiro de 2005 e em contrapartida as universidades participantes, a maioria delas com fins lucrativos, recebem isenções fiscais de tributos que antes recolhiam. $\mathrm{O}$ programa passou por diversas alterações em sua formulação, desde o anúncio oficial de que o projeto de lei seria encaminhado ao Parlamento em 13 de maio de 2004, até a versão definitiva da lei, normalmente, para definir as reivindicações das IES particulares e beneficentes (PINTO; CUNHA, 2013).

O PROUNI é direcionado aos estudantes concluintes do ensino médio da rede pública. Possui reservas de vagas para autodeclarados pardos ou negros, indígenas ou de instituição particular na condição de bolsistas integrais com renda per capita familiar máxima de três salários mínimos, a professores da rede pública de ensino no atual exercício do magistério da educação básica, para os cursos de licenciatura e, para estudantes portadores de deficiências (BRANDÃO, 2005). 
Desde sua criação até o processo seletivo do segundo semestre de 2014, o programa já havia atendido mais de 1,4 milhões de estudantes, sendo 70\% com bolsas integrais (BRASIL, 2015a). É utilizado um sistema informatizado (Sisprouni), que permite transparência ao processo de seleção, em que, o critério se baseia nas notas obtidas no ENEM, proporcionando valorizar por mérito os estudantes que obtiveram um melhor desempenho acadêmico (COSTA; FERREIRA, 2012).

Segundo dados do MEC, em 2005, a renúncia fiscal atingiu R\$ 107 milhões, beneficiando 112.275 estudantes, a um custo por estudante de $\mathrm{R} \$ 970,00$, em contraste com o custo de US\$ 9.000 do estudante no sistema público (OECD, 2007 apud ROCHA, 2011). Em 2007, a renúncia fiscal alcançou R \$ 126 milhões, beneficiando 163.854 estudantes a um custo de $\mathrm{R} \$ 769,00$ por estudante (CORBUCCI, 2007). O Gráfico 1 apresenta a quantidade de bolsas integrais e parciais ofertadas pelo PROUNI de 2005 a 2014.

\section{Gráfico 1 - Quantidade de bolsas ofertadas por ano pelo PROUNI}

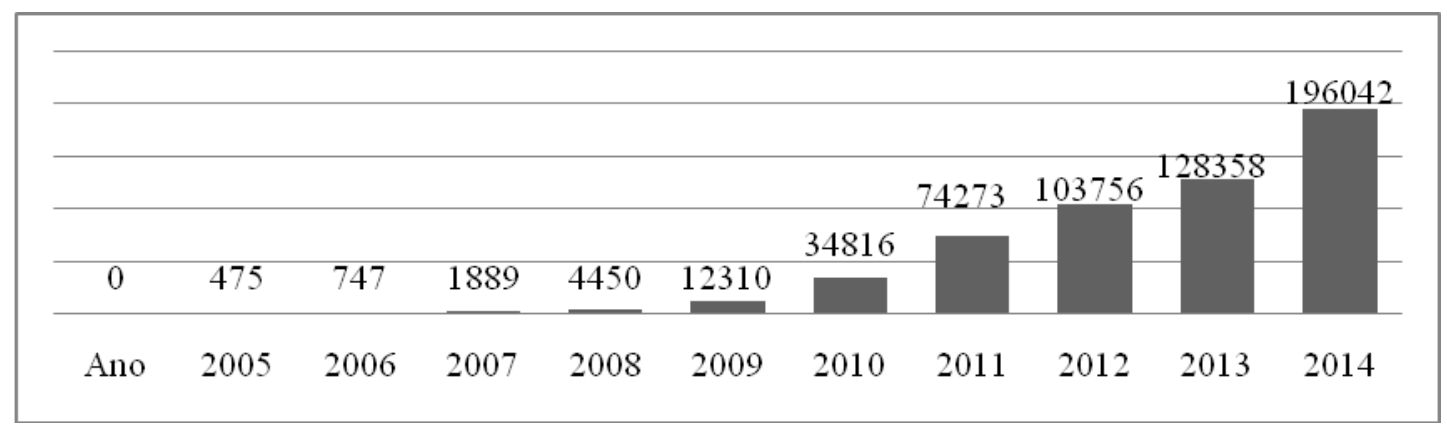

Fonte: Elaborado pelos autores a partir dos dados do INEP/MEC (2015). Disponível em: <http://painel.mec.gov.br/>. Acesso em: 2 abr. 2015.

Para assegurar a permanência do bolsista no curso é disponibilizada a bolsa permanência, que é um benefício com valor máximo correspondente ao praticado na política federal de bolsas de iniciação científica, dedicado especificamente ao custeio das despesas educacionais. É destinado somente aos estudantes matriculados em cursos presenciais com no mínimo 6 semestres de duração e com carga horária média de 6 horas de aula por dia (BRASIL, 2015b).

Outro programa do Governo Federal que auxilia no acesso ao ensino superior privado por meio de financiamento é o FIES que será abordado na seção seguinte.

\section{FIES}

Dados apresentados pelo MEC, de censo efetuado em 2010, mostram que o Brasil tinha 2.365 IES privadas com aproximadamente 6 milhões de alunos regularmente 
matriculados. As instituições privadas representam cerca de $90 \%$ das IES do Brasil. Este panorama destaca a importância do financiamento estudantil para os estudantes, já que a quantidade de IES privadas é maior do que a quantidade de IES públicas. Em 2011, o total de estudantes com algum financiamento, reembolsável ou não, alcançou 1,5 milhões de alunos. Segundo dados do Instituto Nacional de estudos e pesquisas (INEP), entre os alunos que ingressaram em 2011, mais de 1,8 milhões foram em instituições privadas (PINHEIRO, 2013).

Em nível federal, já ocorreram diversas iniciativas de crédito educativo. O primeiro programa de financiamento estudantil, criado em 23 de agosto de 1975, foi o Programa de Crédito Educativo (CREDUC), operacionalizado com recursos do Banco do Brasil, Caixa Econômica Federal (CEF) e bancos comerciais. Em 1999 foi criado o programa de financiamento estudantil (FIES), que veio para substituir o CREDUC durante o governo de Fernando Henrique Cardoso, criado por meio de Medida Provisória nº 1.827/99 (OLIVEIRA; CARNIELLI, 2010).

O FIES é um programa de apoio financeiro que subsidia a graduação de estudantes matriculados em cursos superiores de IES privadas, com conceitos positivos no Exame Nacional de Cursos (ENC), hoje Sistema Nacional de Avaliação do Ensino Superior (SINAES). De acordo com a Portaria Normativa n. 2/2008, são considerados os cursos de graduação com avaliação positiva os que tiverem conceito maior ou igual a três na edição mais atualizada do Exame Nacional de Desempenho dos Estudantes (ENADE) (APRILE; BARONE, 2009).

Inicialmente, era permitido que o estudante financiasse até $70 \%$ do valor da mensalidade do curso. Em setembro de 2005, passou a financiar 50\% e com a Lei 11.552/ 2007, 100\%. De acordo com a Lei $\mathrm{n}^{\circ}$. 10.260/2001, para que o candidato consiga o financiamento, é necessário estar regulamente matriculado na IES, sem a hipótese de se afastar da instituição por um ano, e também que tenha desempenho acadêmico com $75 \%$ de aprovação nas disciplinas do curso. Em 2010 a lei $\mathrm{n}^{\mathrm{o}}$ 12.202/2010 proporcionou mais modificações. O Fundo Nacional de Desenvolvimento da Educação (FNDE) passou a ser o agente operador do programa e, a taxa percentual de juros diminuiu para 3,4\% ao ano. Além disso, o aluno pode solicitar o financiamento em qualquer período do ano (BRASIL, 2015c).

O Gráfico 2 apresenta a quantidade de contratos firmados pelo FIES de 1999 a 2014. 
Gráfico 2 - Número de contratos firmados pelo FIES

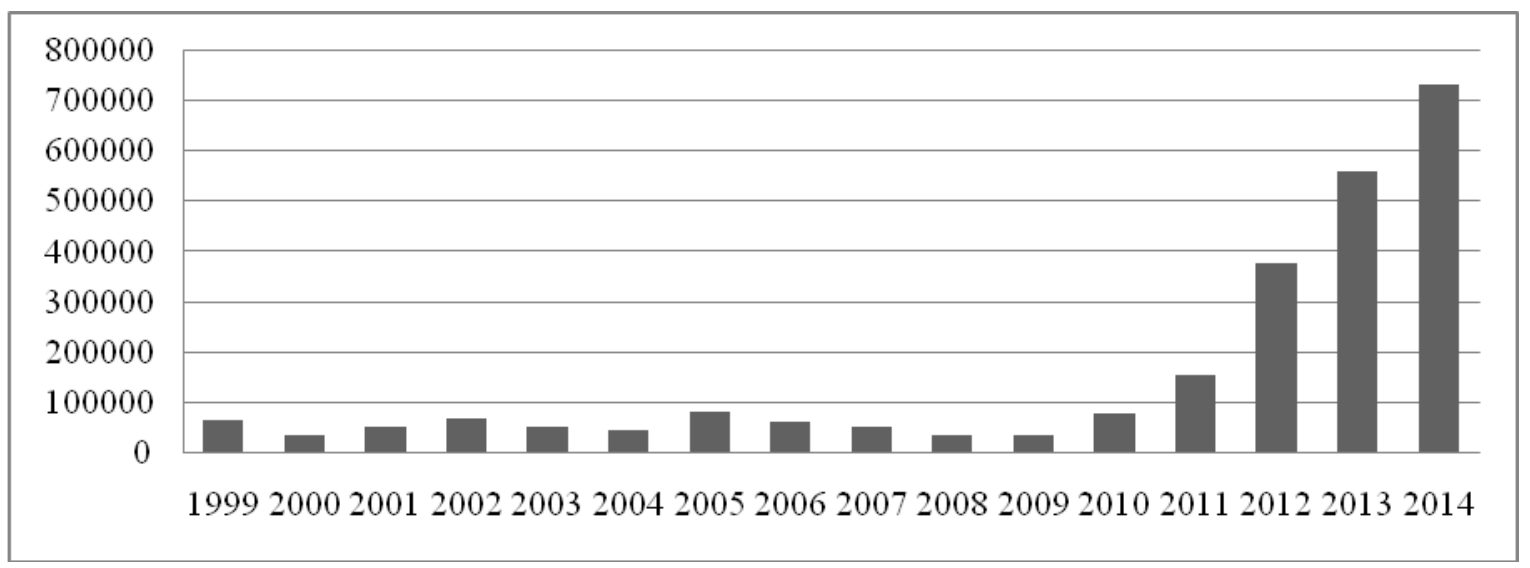

Fonte: Elaborado pelos autores a partir dos dados do MEC (BRASIL, 2015). Disponível em: :<http://painel.mec.gov.br/>. Acesso em: 2 abr. 2015.

São necessários mecanismos que avaliem a qualidade das IES, pois quanto mais estudantes ingressantes nas IES por financiamento maior será a responsabilidade do governo para garantir a qualidade da formação que essas instituições estão disponibilizando para seus alunos (PINHEIRO, 2013). Desde 2010 foi instituído que instituições cadastradas no FIES deveriam ter avaliação positiva (nota mínima de três pontos) no SINAES (BRASIL, 2010).

De acordo com as novas regras do FIES para 2015, os estudantes não poderiam ser beneficiados com mais de uma bolsa, tendo que optar pela bolsa integral do PROUNI ou o FIES. Se o benefício fosse de bolsa parcial do PROUNI, poderia transferir o financiamento para complementar a bolsa. O sistema de cadastro eletrônico passou a exigir mais documentos para as instituições e estudantes e, houve uma redução nas parcelas de pagamentos feitos às universidades, de doze para oito prestações. Foi ainda imposto pelo MEC o limite mínimo de 450 pontos na prova objetiva do ENEM e superior a zero na redação. O governo destacou também que não ratificaria reajustes superiores a 6,41\% pelas instituições de ensino que tiveram contratos firmados (BRASIL. MEC. FIES, 2015).

\section{Qualidade em IES}

De acordo com a Portaria Normativa no 40 de 12 de dezembro de 2007, Art. 33-B, os indicadores de qualidade das IES, calculados pelo INEP são: o Conceito Preliminar de Cursos (CPC), instituído pela Portaria Normativa $\mathrm{n}^{\circ}$ 4, de 05 de agosto de 2008; o Índice Geral de Cursos Avaliados da Instituição (IGC), instituído pela Portaria Normativa $\mathrm{n}^{\circ} 12$, de 05 de setembro de 2008 e o conceito obtido a partir dos resultados do Enade, que avalia o desempenho dos estudantes. 
O IGC avalia as IES públicas ou privadas e o CPC é um indicador de qualidade que avalia os cursos superiores um ano após a realização do ENADE de cada curso. Esses indicadores de qualidade são expressos numa escala de cinco níveis e quando se mostram iguais ou acima de três possuem qualidade satisfatória. Estes indicadores são instrumentos fundamentais de avaliação da educação superior do Brasil (INEP, 2015).

\section{Evasão}

A Comissão Especial do MEC define a evasão como sendo a saída definitiva do aluno do seu curso sem concluí-lo. A evasão é um problema que afeta as instituições de ensino em geral. Os estudantes que começam um curso superior e não concluem geram ociosidade de recursos sociais e econômicos. Nas IES públicas são investimentos que não têm retorno e nas instituições privadas representam fonte de perda de receitas. Nos dois casos, a evasão é uma fonte de ociosidade de docentes, funcionários administrativos e infraestrutura (LOBO, 2012).

As IES privadas investem de $2 \%$ a $6 \%$ de sua receita em marketing para atrair novos alunos a se matricularem em sua instituição, porém, são raras as IES no Brasil que aderem a programas de combate à evasão, com planejamento de ações, acompanhamento dos resultados e coleta de experiências que deram certo (SILVA FILHO, 2007).

Estudos anteriores destacaram que a taxa de evasão no primeiro ano de um curso pode ser duas vezes maior do que nos demais anos. Esse problema aplica-se na relação entre evasão anual e índice de titulação. As IES públicas e privadas e seus estudantes atribuem à falta de recursos financeiros, como sendo um dos principais motivos da evasão. No entanto, este fator não pode ser considerado de forma isolada uma vez que as questões de ordem acadêmica, as expectativas dos estudantes relacionada à sua formação, o desconhecimento do curso, a integração do aluno com a IES, o descontentamento com a infraestrutura universitária, o corpo docente e, problemas de ordem pessoal, podem ser fatores que desestimulam a continuidade do estudante numa IES (SILVA FILHO, 2007).

Em uma análise com dados de 2006 a 2009, Silva (2013), destacou que a reprovação em componentes curriculares, o aumento nas mensalidades, a pendência nos pagamentos, o aumento da idade relativa e o gênero aumentavam as chances de evasão. Entretanto, o autor também identificou que a ausência de renda pessoal, a nota de português no processo seletivo, a participação no programa de nivelamento, a nota intermediária e a bolsa do PROUNI reduziam as chances de desistência dos estudantes. 
Um relatório desenvolvido pelo Núcleo de Apoio ao Ensino de Graduação da USP (NAEG) e pelo Centro de Estudos e Pesquisas em Políticas Públicas de Educação (CEPPPE) (2004), indicou que aparece como principal motivo da evasão com 44,5\% a dificuldade de escolha do curso, devido à falta de informação ou pressão, a estrutura do curso com $30,7 \%$, a insatisfação com o mercado de trabalho da profissão escolhida com 13,4\% e de motivos pessoais com 11,4\% (RIBEIRO, 2005). O Quadro 1 mostra a o percentual de evasão em IES no Brasil de 2005 a 2013.

Quadro 1 - Evasão em IES no Brasil

\begin{tabular}{|c|c|}
\hline \multicolumn{2}{|c|}{ Evasão em IES no Brasil } \\
\hline 2005 & $22 \%$ \\
\hline 2006 & $21,7 \%$ \\
\hline 2007 & $22 \%$ \\
\hline 2008 & $22,2 \%$ \\
\hline 2009 & $20,9 \%$ \\
\hline 2010 & $15,0 \%$ \\
\hline 2011 & $18,7 \%$ \\
\hline 2012 & $19,3 \%$ \\
\hline 2013 & $18,4 \%$ \\
\hline
\end{tabular}

Fonte: Elaborado a partir de: SILVA FILHO, Roberto L. Lobo et al. A evasão no ensino superior brasileiro. Cadernos de Pesquisa, São Paulo, v. 37, n. 132, p. 641-659, 2007; SILVA, Adriano M.; SAUAIA, Antonio C. Aidar. Evasão em qualidade em instituições de ensino superior privadas: uma análise da economia de custos de transação.Administração: Ensino e Pesquisa, Rio de Janeiro, v. 15, n. 4, p. 805, 2014; BRASIL. MEC. 2015d. Disponível em: <http://portal.mec.gov.br/index.php?option=com_content\&view=article \&id=18049:numero-de-contratos-do-fies-ultrapassa-300-mil-em-2012\&catid=372>. Acesso em: 20 mar. 2015.

De acordo com Silva Filho (2007), o cálculo utilizado para evasão é a comparação entre o número de alunos que se matricularam em um determinado ano, subtraídos os alunos que concluíram o curso com o número de alunos matriculados no ano seguinte, subtraindo-se deste último total os ingressantes do ano atual. Sendo assim, mede-se a perda de alunos de um ano para outro (evasão anual). O cálculo do percentual da evasão referente ao ano n é dado por:

$$
1-\frac{\left[M_{(t)}-I_{(t)}\right]}{\left[M_{(t-1)}-C_{(t-1)}\right]}
$$

Onde:

E é a taxa percentual de evasão,

$\mathbf{M}$ é número de matriculados,

C é o número de concluintes,

I é o número de ingressantes,

t é o ano em estudo,

(t-1) é o ano anterior. 
Pesquisa realizada por Silva Filho (2007) destaca que, no período de 2000 e 2005, a evasão média em todas as IES do Brasil foi de $22 \%$, sendo que nas públicas alcançou $12 \%$ e nas privadas $26 \%$.

Buscando a igualdade e oportunidade de acesso ao ensino superior é imprescindível à implementação e o acompanhamento de políticas públicas educacionais, porém não é a única condição para que ocorra a democratização efetiva nas IES privada no combate à evasão (BARDAGI, 2007).

\section{Metodologia}

A pesquisa realizada nesse trabalho é quantitativa e classificada pelo objetivo como descritiva e por objeto como bibliográfica. Isto porque descreve as características de alguns objetos e estabelece relação entre as variáveis analisadas no estudo. Quanto aos procedimentos esse trabalho é de abordagem indireta. É uma pesquisa dedutiva que parte de leis gerais para compreender as questões (PINHEIRO, 2010).

Para atingir os objetivos da pesquisa foram analisados os dados disponíveis pelo BRASIL (2015d) e INEP (2015). Foi utilizada a técnica de análise de painéis com o software GRETL. A evasão foi obtida ao nível dos Estados e Distrito Federal e calculada conforme a Equação 1. Foram coletados dados da evasão de 2005 a 2013 nos 26 Estados juntamente com o Distrito Federal totalizando 243 observações (27×9), ou seja, um painel balanceado.

O modelo estimado foi baseado na Equação 2:

$$
E V A S A O_{i t}=\alpha_{i}+\beta_{1} P R O U N I_{i t}+\beta_{2} F_{I E S}
$$

\section{Em que:}

$\mathrm{i}=1,2,3, . ., 27$ são os Estados juntamente com o Distrito Federal $\mathrm{t}=2005,2006, \ldots, 2013$, ou seja, o ano em que a evasão foi calculada.

A métrica de qualidade foi obtida por indicadores disponíveis no site do INEP denominados Índice geral de Cursos (IGC) e o Conceito Preliminar de Cursos (CPC) de 2007 a 2013. O IGC avalia as IES públicas ou privadas e o CPC é um indicador de qualidade que avalia os cursos superiores um ano após a realização do ENADE de cada curso, sendo baseado na avaliação do desempenho de estudantes, infraestrutura, corpo docente e recursos didático-pedagógicos (INEP, 2015). 


\section{Resultados}

Nesta seção são apresentados os resultados com uma análise descritiva para em seguida apresentar os resultados da estimação e a relação entre o FIES e qualidade das IES que aderiram ao programa.

\subsection{Análise descritiva}

O Quadro 2 apresenta o resultado descritivo das quantidades de bolsas ofertadas pelo PROUNI, contratos firmados pelo FIES e a evasão média nacional a cada ano.

Quadro 2 - Bolsas do PROUNI, Contratos do FIES e evasão média nacional nas IES privadas

\begin{tabular}{|c|c|c|c|c|c|c|c|c|c|}
\hline & $\mathbf{2 0 0 5}$ & $\mathbf{2 0 0 6}$ & $\mathbf{2 0 0 7}$ & $\mathbf{2 0 0 8}$ & $\mathbf{2 0 0 9}$ & $\mathbf{2 0 1 0}$ & $\mathbf{2 0 1 1}$ & $\mathbf{2 0 1 2}$ & $\mathbf{2 0 1 3}$ \\
\hline (1) Bolsas do PROUNI & 475 & $\mathbf{7 4 7}$ & 1889 & 4450 & 12310 & 34816 & 74273 & 103756 & 128358 \\
\hline (2) Contratos do FIES & 80961 & 60092 & 49770 & 33319 & 32741 & 76171 & 154257 & 377821 & 559963 \\
\hline TOTAL (1+2) & 81436 & 60839 & 51659 & 37769 & 45051 & 110987 & 228530 & 481577 & 688321 \\
\hline Evasão média nacional & 0,22 & 0,217 & 0,22 & 0,222 & 0,209 & 0,15 & 0,187 & 0,193 & 0,184 \\
\hline
\end{tabular}

Fonte: Elaborado pelos autores a partir dos dados do estudo.

Pela análise do Quadro 2, pode-se constatar que tanto o número de bolsas do PROUNI quanto o número de contratos firmados pelo FIES tiveram aumento significativo no período de análise. Já a evasão, diminuiu de maneira considerável no ano de 2010 sendo que continuou a aumentar a partir de 2011.

\subsection{Análise de painel}

A estimação da Equação 2, por meio da análise de painéis, comparou cinco modelos de regressão. No modelo de Mínimos Quadrados Agrupados (MQA) (Pooled Ordinary Least Squares) os dados de cortes transversais foram agrupados e estimados de maneira conjunta. Além deste modelo, também foram estimados outros quatro modelos: pela técnica Entregrupos (MEG), Efeitos Fixos (MEF) e Efeitos Aleatórios (MEA). Os resultados da estimação são apresentados no Quadro 3.

\section{Quadro 3 - Resultados da estimação dos modelos de painéis}

\begin{tabular}{|c|c|c|c|c|}
\hline \multirow{2}{*}{ Modelo } & \multicolumn{3}{|c|}{ Coeficientes } & \multirow{2}{*}{$\begin{array}{c}\text { Avaliação do } \\
\text { modelo }\left(\mathbf{R}^{2}\right)\end{array}$} \\
\hline & Constante & PROUNI & FIES & \\
\hline MQA & $\begin{array}{l}0,232 \\
(p<0,00)\end{array}$ & $\begin{array}{l}-7,51701 e-06 \\
(p=0,269)\end{array}$ & $\begin{array}{l}2,03068 \mathrm{e}-06 \\
(p=0,249)\end{array}$ & 0,02 \\
\hline MEG & $\begin{array}{l}0,224 \\
(p<0,00)\end{array}$ & $\begin{array}{l}3,57541 e-06 \\
(p=0,744)\end{array}$ & $\begin{array}{l}6,00449 e-07 \\
(p=0,852)\end{array}$ & 0,126 \\
\hline MEF & $\begin{array}{l}0,237 \\
(p<0,00)\end{array}$ & $\begin{array}{l}-1,1743 e-05 \\
(p=0,074)\end{array}$ & $\begin{array}{l}2,36001 \mathrm{e}-06 \\
(p=0,172)\end{array}$ & 0,27 \\
\hline MEA & $\begin{array}{l}0,235 \\
(p<0,00)\end{array}$ & $\begin{array}{l}-9,62172 e-06 \\
(p<0,00)\end{array}$ & $\begin{array}{l}2,20393 e-06 \\
(p<0,00)\end{array}$ & 0,041 \\
\hline
\end{tabular}

Fonte: Elaborado pelos autores a partir dos dados do estudo. 
Conforme se pode verificar no Quadro 3, na estimação por efeitos aleatórios (MEA), diferentemente dos outros modelos, MQA, MEG e MEF, os coeficientes do PROUNI e FIES foram significantes. $\mathrm{O}$ valor do R2, na estimação por efeitos aleatórios, foi de 0,041 , superior apenas ao do modelo MQA. O resultado indica que a evasão é reduzida quando há o incremento de bolsas do PROUNI e aumentada quando há o incremento de contratos do FIES. Sendo que, de maneira comparativa, o impacto maior na evasão é ocasionado pelo PROUNI em relação ao FIES. O Teste de Breusch-Pagan que avalia a adequação do modelo de efeitos aleatórios, em relação ao MQA, indicou a superioridade do modelo $(\mathrm{p}<0,001)$. O fato do modelo de efeitos aleatórios ter sido significante implica em evidências de que houve variância significativa ao longo do tempo entre e intra-grupos. O modelo final ficou estimado conforme exibido na Equação 3.

$$
\text { EVASAO }_{i t}=(0,2335063)+\left(9,62172 \mathrm{e} 06 P_{R O U N I}\right)+\left(2,20393 \mathrm{e} 06 \mathrm{FIES}_{i t}\right)
$$

Para investigar o efeito positivo do FIES na evasão foi analisado a quantidade de contratos do financiamento e qualidade das IES e dos cursos.

\subsection{FIES e qualidade}

Utilizando os dados disponíveis do IGC e CPC disponibilizados pelo INEP, foi possível obter os resultados apresentados nesta seção. O Quadro 4 mostra o número de contratos do FIES e a avaliação de 0-5 das IES:

\section{Quadro 4 - Total de contratos firmados pelo FIES e IGC das IES}

\begin{tabular}{|c|c|}
\hline IGC & Total contratos \\
\hline 0 & 81.295 \\
\hline 1 & 152 \\
\hline 2 & 197.279 \\
\hline 3 & 1.736 .841 \\
\hline 4 & 136.742 \\
\hline 5 & 1.700 \\
\hline
\end{tabular}

Fonte: Elaborado pelos autores a partir dos dados do estudo.

Pela análise do Quadro 4, pode-se observar que as IES que tiveram a maior quantidade de contratos do FIES, com um total de 1.736.841, obtiveram um IGC de 3. As instituições com avaliação 0 não obtiveram conceito em determinados anos, mas proporcionaram o 
financiamento à 81.295 estudantes. O Quadro 5 mostra o CPC de 0-5 dos cursos de determinadas IES privadas e o percentual de contratos firmados do FIES de 2007 a 2013.

\section{Quadro 5 - Total de contratos firmados pelo FIES e o CPC das IES}

\begin{tabular}{|c|c|c|}
\hline CPC & Total de contratos & $\%$ \\
\hline 0 & 57921 & $49,66 \%$ \\
\hline 1 & 63 & $0,05 \%$ \\
\hline 2 & 3073 & $2,63 \%$ \\
\hline 2 a 3 & 733 & $0,63 \%$ \\
\hline 3 & 31801 & $27,26 \%$ \\
\hline 3 a 4 & 4385 & $3,76 \%$ \\
\hline 4 & 16290 & $13,97 \%$ \\
\hline 4 a 5 & 1660 & $1,42 \%$ \\
\hline 5 & 711 & $0,61 \%$ \\
\hline
\end{tabular}

Fonte: Elaborado pelos autores a partir dos dados do estudo.

Pode-se verificar no Quadro 5 que o maior percentual de contratos foi verificado nos cursos que obtiveram CPC 0 ou não obtiveram conceito, seguido de 27,26\% de cursos com CPC 3.

\section{Discussão dos resultados}

Este estudo contribuiu com o estudo da temática da evasão e de políticas públicas para a sua contenção com o levantamento dos dados da avaliação de quatro modelos de regressão por meio da análise de painéis. Na estimação por efeitos aleatórios (MEA), os coeficientes do PROUNI e FIES foram significantes, mas o PROUNI se mostrou como uma política mais eficaz do que o FIES na contenção da evasão. Para isso, foram coletados os dados referentes ao número de bolsas integrais e parciais ofertadas pelo PROUNI e a quantidade de contratos firmados pelo FIES de 2005 a 2013 disponibilizados na plataforma de indicadores do Governo Federal.

Os dados disponíveis pelo INEP foram fundamentais para a obtenção do IGC e do CPC das IES privadas e a posterior comparação de sua qualidade com os contratos firmados pelo FIES. Desta forma, pode-se concluir que as IES com a maior quantidade de contratos do FIES tiveram o IGC 3. Já os cursos que tiveram maior quantidade de contratos firmados com o FIES foram os que tinham CPC de 0 ou apresentaram-se sem conceito.

\section{Considerações finais}

No Brasil, houve uma ampliação da quantidade de IES e vagas ofertadas no setor privado, por isso, é necessário que o Estado se atenha a políticas públicas voltadas ao acesso 
de estudantes de baixa renda ao ensino superior. O PROUNI e o FIES são exemplos de políticas públicas que possibilitam incluir estudantes que não podem arcar com os custos de uma IES privada.

Desta forma, esta pesquisa concluiu que o PROUNI tem sido uma política mais eficaz do que o FIES no que tange a contenção da evasão. Com os resultados obtidos neste estudo, gestores públicos podem direcionar políticas públicas que tenham eficácia não somente no acesso ao ensino superior por meio de IES privadas, mas também na análise do impacto de tais políticas na contenção da evasão haja vista seus efeitos adversos em relação à ociosidade de recursos e perda de receita.

Futuros estudos podem investigar melhor o fato do FIES não ter tido impacto negativo no fenômeno da evasão. Possíveis análises posteriores poderiam identificar eventual viés de seleção na concessão de contratos do FIES. Tal como evidenciaram Silva e Sauaia (2014), que IES privadas com menor nível de qualidade possivelmente têm evasão mais elevada, caso o FIES seja concedido em grande parte para tais IES, seria uma possível explicação do resultado aqui obtido. Tal fato pode ter feito com que o Ministério da Educação restringisse os critérios de concessão de contratos do FIES a depender da qualidade da IES.

\section{Referências}

1. APRILE, Maria R.; BARONE, Rosa E. Mirra. Educação superior: políticas públicas para inclusão social. Revista Ambiente Educação, São Paulo, v. 2, n. 1, p. 39-55, 2009.

2. BARDAGI, Marúcia P. Evasão e comportamento vocacional de universitários: estudos sobre o desenvolvimento de carreira na graduação. 2007. Tese (Doutorado) Universidade Federal do Rio Grande do Sul, Porto Alegre, 2007.

3. BONETI, Lindomar Wessler (Coord.). Educação, exclusão e cidadania. 3. ed. Ijui: Editora UNIJUI, 2003.

4. BRANDÃO, Carlos da F. Política educacional para a educação superior brasileira na última década. Piracicaba: Impulso, 2005.

5. BRASIL. Lei $\mathrm{n}^{\circ}$. 11.096, de 13 de janeiro de 2005. Institui o Programa Universidade para Todos - PROUNI, regula a atuação de entidades beneficentes de assistência social no ensino superior; altera a Lei no10.891, de 9 de julho de 2004, e dá outras providências. Diário Oficial da União, Brasília, DF, 14 jan. 2005.

6. BRASIL. Senado Federal. Texto sobre políticas públicas. 2015. Disponível em: <http://www.senado.gov.br/senado/conleg/textos_discussao.html.>. Acesso em: 26 mar. 2015.

7. BRASIL. Ministério da Educação (MEC). Ministério da Educação divulga regras para inscrições no FIES. 2010. Disponível em: 
<http://portal.mec.gov.br/docman/maio-2010-pdf/4791-inscricoes-fies-regras-sesu>. Acesso em: 26 set. 2015.

8. BRASIL. Ministério da Educação (MEC). O Programa Universidade para Todos. 2015a. Disponível em: <http://prouniportal.mec.gov.br/o-programa〉. Acesso em: 20 mar. 2015.

9. BRASIL. Ministério da Educação (MEC). O Programa Bolsa Permanência. 2015b. Disponível em: <http://prouniportal.mec.gov.br/bolsa-permanencia〉. Acesso em: 19 mar. 2015.

10. BRASIL. Senado Federal. Texto sobre políticas públicas. 2015. Disponível em: <http://www.senado.gov.br/senado/conleg/textos_discussao.html.>. Acesso em: 26 mar. 2015.

11. BRASIL. Ministério da Educação (MEC). O Programa de Financiamento Estudantil. 2015c. Disponível em: <http://sisfiesportal.mec.gov.br/fies.html>. Acesso em: 20 mar. 2015.

12. BRASIL. Ministério da Educação (MEC). Divulgação do número de contratos do FIES. 2015d. Disponível em:<http://portal.mec.gov.br/index.php?option=com_content\&view=article\&id=1804 9:numero-de-contratos-do-fies-ultrapassa-300-mil-em-2012\&catid=372>. Acesso em: 20 mar. 2015.

13. BRASIL. Ministério da Educação (MEC). Painel de dados da educação. Disponível em: : <http://painel.mec.gov.br/>, acessado em 02/04/2015

14. BRASIL. Ministério da Educação (MEC). FIES. MEC relata mudanças no FIES. 2015. Disponível em: 〈http://www.fies2015.com/mudancas-no-fies-2015.html〉 Acesso em: 22 jul. 2015.

15. CORBUCCI, Paulo R. Desafios da educação superior e desenvolvimento no Brasil. Brasília: IPEA, 2007. Texto para discussão n. 1287.

16. COSTA, Jordanna M. Nunes; FERREIRA, Jesse R. Programa Universidade para todos (Prouni): política pública afirmativa ou mecanismo de consolidação do setor privado na educação superior brasileira. In: CONFERÊNCIA FORGES - Fórum da Gestão do Ensino Superior nos Países e Regiões de Língua Portuguesa, 2. 2012,

Macau. Documentos... 2012.

17. COSTA, Danielle Dias da; FERREIRA, Norma-Iracema de Barros. O PROUNI na educação superior brasileira: indicadores de acesso e permanência. Avaliação, Campinas; Sorocaba, v. 22, n. 1, p. 141-163, 2017.

18. CUNHA, Carla G. Soares da. Avaliação de políticas públicas e programas governamentais: tendências recentes e experiências no Brasil. Rio Grande do Sul: Secretaria de Coordenação e Planejamento, 2006.

19. ROCHA, M. C. PROUNI: um estudo das práticas e percepções sociais dos alunos bolsistas. In: JORNADAS DE JÓVENES INVESTIGADORES, 19., 2011, Ciudade del Este. [Anais...]. Ciudade del Este: Ediciones UNE, 2011.

20. FONTELE, Tereza Lúcia Lima; CRISÓSTOMO, Vicente Lima. PROUNI - pontos controversos sob a análise de alunos bolsistas. Avaliação, Campinas; Sorocaba, v. 21, n. 3, nov. 2016. 


\section{INSTITUTO NACIONAL DE ESTUDOS E PESQUISAS EDUCACIONAIS} ANÍSIO TEIXEIRA (INEP). 2015. Indicadores da Educação Superior. Disponível em: <http://portal.inep.gov.br/educacao-superior/indicadores>. Acesso em: 27 ago. 2015.

22. LOBO, Maria Beatriz de C. Melo. Panorama da evasão no ensino superior brasileiro: aspectos gerais das causas e soluções. Cadernos ABMES, Brasília, n. 25, p. 1-23, dez. 2012.

23. MUGNOL, Márcio; GISI, Maria Lourdes. Avaliação de políticas públicas educacionais: os resultados do Prouni. CONJECTURA: filosofia e educação, Caxias do Sul, p. 122-139, 2013.

24. OLIVEIRA, Zenaide dos R. Borges Balsanulfo de; CARNIELLI, Beatrice Laura. Fundo de Financiamento ao Estudante do Ensino Superior (FIES): visão dos estudantes. Jornal de Políticas Educacionais, Curitiba, n. 7, p. 35-40, jan./jun. 2010.

25. PINHEIRO, José Mauricio dos Santos. Da Iniciação Científica ao TCC: uma abordagem para os cursos de tecnologia. Rio de Janeiro: Ciência Moderna, 2010.

26. PINHEIRO, Wesley M. Captação X inclusão: duas faces do financiamento estudantil. Revista Espaço Acadêmico, Maringá, v. 13, n. 149, p. 01-13, 2013.

27. PINTO, Marialva M.; CUNHA, Maria Isabel. Qualidade da educação superior: o PROUNI na inclusão e democratização do acesso. Revista educação em rede: formação e prática docente, Cachoeirinha, v. 2, n. 2, 2013.

28. RIBEIRO, Marcelo A. O projeto profissional familiar como determinante da evasão universitária: um estudo preliminar. Revista Brasileira de Orientação Profissional, Florianópolis, v. 6, n. 2, p. 55-70, 2005.

29. SILVA, Glauco Peres da. Análise de evasão no ensino superior: uma proposta de diagnóstico de seus determinantes. Avaliação, Campinas, Sorocaba, v. 18, n. 2, jul. 2013.

30. SILVA, Adriano M.; SAUAIA, Antonio C. Aidar. Evasão em qualidade em instituições de ensino superior privadas: uma análise da economia de custos de transação. Administração: Ensino e Pesquisa, Rio de Janeiro, v. 15, n. 4, p. 805, 2014.

31. SILVA FILHO, Roberto L. Lobo et al. A evasão no ensino superior brasileiro. Cadernos de Pesquisa, São Paulo, v. 37, n. 132, p. 641-659, 2007.

32. SOUZA, Celina et al. Políticas públicas: uma revisão da literatura. Sociologias, Porto Alegre, v. 8, n. 16, p. 20-45, 2006.

\footnotetext{
Adriano Maniçoba da Silva - Instituto Federal de São Paulo Suzano | SP | Brasil. Contato: adrianoms@ifsp.edu.br

Beatriz Carolini Silva Santos - Instituto Federal de São Paulo Suzano | SP | Brasil. Contato: bia_carolini22@hotmail.com
} 